\title{
A informação como assunto no direito e na ciência da informação: um estudo comparativo a partir da realidade brasileira
}

\author{
La información como tema en el derecho y en la ciencia de la información:
} un estudio comparativo a partir de la realidad brasileña

Information as a subject in law and in information science: a comparative study based on the Brazilian reality

\section{João Carlos Gardini Santos (1), José Augusto Chaves Guimarães (1), Juan-Carlos FERNÁNDEZ-MOLINA (2)}

(1) Universidade Estadual Paulista Júlio de Mesquita Filho - UNESP, Brasil, jcgardini@gmail.com, guima@marilia.unesp.br (2) Universidad de Granada, España, jcfernan@ugr.es

\begin{abstract}
Resumen
Este artículo busca delinear hasta cómo se presenta el concepto de información en las áreas de Derecho y Ciencias de la Información en Brasil, buscando identificar sus características descriptivas en sus aspectos convergentes y complementarios. Para ello, se realizó una revisión bibliográfica sobre el tema seguida de la aplicación de la metodología de análisis de contenido (Bardin, 2009) en función de las categorías procesos, objetivos, elementos, características y derechos derivados de la información. Los resultados revelan una convergencia entre el Derecho y la Ciencia de la Información en los aspectos relacionados con el acto de informar o informar a alguien, la transmisión de conocimiento como el objetivo de la información y la necesidad de un soporte para dar materialidad a la información. En el caso de las ciencias de la información, se hace mayor hincapié en los procesos informacionales de producción, organización y uso de la información, y sus dimensiones conceptuales (como conocimiento, como proceso y como cosa). En el caso del derecho, se hace hincapié en los efectos o garantías que surgen del acceso a la información y los principios jurídicos inherentes al derecho a la información (por ejemplo, no divulgación, publicidad, universalidad, etc.). Se puede concluir que el uso cada vez más técnico del término en la Ley requiere una referencia teórica a la Ciencia de la Información, para que su dimensión conceptual pueda ser delimitada de forma más específica, de cara a la consolidación de su terminología.
\end{abstract}

Palabras clave: Ley de acceso a la información. Información. Información jurídica. Análisis de contenido. Organización de la información.

\section{Introdução}

Após o surgimento do conceito de informação na Lei de Acesso à Informação (Lei no 12.527/2011 - LAI) o termo passou a ser utilizado, pelo Supremo Tribunal Federal do Brasil (STF), com maior parcimônia e cuidado semântico, razão pela qual tornou-se necessária a identificação das categorias temáticas que o permeiam a fim

\begin{abstract}
This paper seeks to delineate the extent to which the concept of information is presented in the areas of Law and Information Science in Brazil, seeking to identify descriptive features in their convergent and complementary aspects. For this, a literature review on the subject followed by the application of the content analysis methodology (Bardin, 2009) was carried out based on the categories processes, objectives, elements, features and rights arising from the information. The results reveal a convergence between the Law and the Information Science in aspects related to the act of informing or informing someone, the transmission of knowledge as the objective of the information and the need for a support to give materiality to the information. In the case of Information Science, there is a greater emphasis on the informational processes of production, organization and use of information and its conceptual dimensions (as knowledge, as a process and as a thing). In the case of Law, the emphasis is on the effects or guarantees arising from access to information and the legal principles inherent in the right of information (for example, non-disclosure, publicity, universality etc.). It can be concluded that the increasingly technical use of the term in Law requires the theoretical reference of Information Science, so that its conceptual dimension can be delimited more specifically, with a view to the sedimentation of its terminology.
\end{abstract}

Keywords: Access to information act. Information. Legal information. Content analysis. Information organization.

de que ele seja caracterizado como um instituto jurídico no âmbito jurisprudencial e possa ser mais desenvolvido e representado enquanto um termo descritor de um tesauro jurídico.

Nesse sentido, e para que se possa contribuir para um uso cada vez mais técnico do termo, necessário se torna analisar como se dá essa di- 
mensão conceitual, no âmbito do Direito e da Ciência da Informação, que possa subsidiar uma delimitação mais específica com vistas à sedimentação de sua terminologia. Para que isso ocorra, utilizando a metodologia da análise de conteúdo (Bardin, 2008), analisa-se, no âmbito do Brasil, a literatura do Direito e da Ciência da Informação relativa à questão da informação, notadamente sob o aspecto conceitual, de modo a identificar seus aspectos convergentes e as diversidades de abordagem.

Espera-se, com isso, delinear em que medida o conceito de informação se apresenta nos âmbitos do Direito e da Ciência da Informação, no Brasil, buscando identificar traços descritivos em seus aspectos convergentes e complementares e contribuir para os processos de caracterização da informação como descritor de tesauros, em especial os tesauros jurídicos, uma vez que esse termo vem assumindo, cada vez mais a condição de instituto jurídico (Santos; Guimarães, 2016).

\section{Metodologia}

Partiu-se de uma revisão de literatura sobre a informação no Direito brasileiro assim como na teoria de Ciência da Informação, uma vez que esse método visa a fornecer fundamentação teórica à pesquisa, além de permitir que seja identificado qual é o atual estágio do tema de pesquisa. Destaca-se, ainda, que a revisão bibliográfica permite "[...] ao investigador a cobertura de uma gama de fenômenos muito mais ampla do que aquela que poderia pesquisar diretamente" (Gil, 2010, p. 30).

Uma vez devidamente analisadas as fontes e destacadas as menções à concepção de informação, aplicou-se a metodologia de análise de conteúdo (Bardin, 2008), a qual pressupõe um procedimento de decomposição do todo em suas diversas partes constitutivas a partir de uma sistemática que se desenvolve em três fases: préanálise, na qual se escolhem os documentos para a formação do corpus, além da formulação das hipóteses e da definição dos objetivos da análise; exploração do material, quando se efetiva o processo de categorização do conteúdo; e, por último, o tratamento dos resultados, quando se realizam as inferências e interpretações (Guimarães; Sales, 2010).

Para tanto, estabeleceram-se as seguintes categorias de análise: Processos, Objetivos, Elementos, Características e Direitos e garantias decorrentes da informação, cujos resultados são apresentados e discutidos na seção 5 .

\section{A dimensão conceitual da informação no Direito brasileiro}

No âmbito do Direito, necessitamos recorrer à doutrina e à legislação para definir e caracterizar a informação. Por se tratar da norma de maior importância no âmbito jurídico nacional, inicialmente, realizaremos uma análise acerca dos aspectos constitucionais que envolvem o direito fundamental de acesso à informação e, em seguida, dos aspectos infraconstitucionais que orbitam esse direito.

De pronto, devemos observar que o direito à informação está previsto na Constituição Federal de 1988 (CF/88), mas tal direito já se encontrava previsto na redação original da Constituição de 1967, assim como na Emenda Constitucional $n^{\circ}$ 1 de 1969.

A CF/88 garante o direito à informação no artigo $5^{\circ}$, XIV e XXXIII, no artigo 37 , § $3^{\circ}$, II e, por fim, no artigo $216, \S 2^{\circ}$. O artigo $5^{\circ}$ está inserido no Título II - Dos Direitos e Garantias Fundamentais -, o artigo 37 no Título III - Da Organização do Estado - e o artigo 216 no Título VIII - Da Ordem Social.

Por estar previsto no artigo $5^{\circ}$, trata-se precipuamente de um direito fundamental que, como tal, apresenta as seguintes características: a) universalidade (aplica-se a todas as pessoas, sem distinção de qualquer natureza); b) irrenunciabilidade (ninguém pode deles renunciar); c) inalienabilidade (são indisponíveis, não admitindo alienação); d) imprescritibilidade (não se perdem ao longo do tempo). Tais direitos, como destaca Novelino (2011) apresentam caráter vinculante e obrigatório, de tal forma que a ninguém é permitido escusar-se cumprir/respeitar um direito fundamental.

Dentre os diversos vieses que envolvem a questão da informação na CF/88 destaca-se, primeiramente, o fato de que o direito de acesso à informação abriga a questão da liberdade de informação prevista no artigo $5^{\circ}, \mathrm{XIV}$, que assegura o amplo acesso à informação resguardando, quando profissionalmente necessário, o sigilo da fonte, e que não deve ser confundido com a liberdade de expressão do pensamento. Por um lado, o direito de acesso à informação abrange o direito de todas as pessoas terem o acesso amplo e geral às informações (o direito de informar e de ser informado é um dos pressupostos básicos de existência das democracias modernas) e, por outro, a liberdade de expressão do pensamento que, além de envolver o direito de emitir uma opinião, está intrinsicamente relacionada à liberdade de impressa, sendo essa um reflexo daquela. 
Em segundo lugar temos o artigo $5^{\circ}, \mathrm{XXXIII} \mathrm{da}$ $\mathrm{CF} / 88$ que trata do direito que todas as pessoas têm de "[...] receber dos órgãos públicos informações de seu interesse particular, ou de interesse coletivo ou geral, que serão prestadas no prazo da lei, sob pena de responsabilidade, ressalvadas aquelas cujo sigilo seja imprescindível à segurança da sociedade e do Estado" (Brasil, 1988). Trata-se do direito de acesso à informação por parte dos órgãos públicos, conforme explicado pelo Ministro Roberto Barroso no Mandado de Segurança $n^{\circ} 28.178$ do Supremo Tribunal Federal. Observamos, nesse caso, que a regra é a publicidade das informações e que o sigilo é a exceção, conforme disposto na parte final desse mandamento constitucional. A isso acrescenta-se a complementação advinda do direito de obtenção de certidões, previsto no artigo $5^{\circ}$, XXXIV, "b", do mesmo diploma legal. Essa norma prevê que todas as pessoas têm o direito de obter certidões em repartições públicas para a defesa de direitos e esclarecimentos de situações pessoais independentemente do pagamento de taxas.

Outra citação constitucional referente à informação está prevista no artigo $37, \S 3^{\circ}$, II o qual prevê que à lei compete regulamentar os meios de participação dos cidadãos na administração pública direta e indireta, regulamentando o acesso dos usuários aos registros administrativos e às informações sobre os atos de governo, observando o direito disposto no inciso XXXIII do artigo $5^{\circ}$ e a inviolabilidade da intimidade, da vida privada, da honra e da imagem das pessoas. Nesse caso, observamos novamente o conflito entre a regra, a publicidade, e a exceção, o sigilo. Lenza (2015, p. 886) explica que nos casos em que se objetiva violar o sigilo, o "ônus argumentativo de demonstrar a caracterização de uma dessas circunstâncias incumbiria a quem pretendesse afastar a regra geral da publicidade". Destaca-se que a violação indevida das informações de caráter estritamente pessoal é passível que indenização por danos materiais e morais dela decorrente.

Nesse contexto é possível a existência de conflito entre o direito fundamental da privacidade e direito fundamental da liberdade de informação. Apesar da solução do conflito, a fim de verificar qual direito deve prevalecer, somente poder ser analisada no caso concreto, existem alguns critérios de ponderação, criados pela doutrina, que objetivam auxiliar na solução desse conflito. São esses critérios: “i) licitude da informação; ii) forma adequada de transmissão; iii) contribuição para o debate de interesse geral ou relevância para a formação da opinião pública, eixo em torno do qual gira o direito à informação" (Novelino, 2011, p. 455).
A Constituição aborda, ainda sobre a questão da informação, no artigo $216, \S 2^{\circ}$, a questão da gestão da documentação governamental. Esse dispositivo prevê que "cabe à administração pública, na forma da lei, a gestão da documentação governamental e as providências para franquear sua consulta a quantos dela necessitem" (Brasil, 1988). Esse dispositivo é regulamentado pela Portaria $n^{\circ} 293$ de 01 de abril de 2013 do Ministério da Ciência Tecnologia e Inovação. O Anexo Política de Gestão Documental dessa norma define, no artigo $1^{\circ}, \mathrm{VI}$ essa atividade como o "conjunto de procedimentos e operações técnicas referentes à produção, classificação, tramitação, uso, avaliação e arquivamento de documentos em fase corrente e intermediária, visando a sua eliminação ou recolhimento para guarda permanente" (Brasil, 2013).

Além disso, essa mesma norma conceitua, no artigo $1^{\circ}, \mathrm{VII}$, o acesso à informação como o "ato de franquear o acesso/conhecimento a dados, processados ou não, que podem ser utilizados para produção e transmissão de conhecimento, contidos em qualquer meio, suporte ou formato". Essa definição possui diversos elementos daqueles encontrados no conceito de informação trazido pela Lei de Acesso à Informação (LAl), abordados a seguir.

Por fim, um último aspecto relativo à informação encontrado na Constituição de 1988 é a possibilidade da impetração do habeas data. Trata-se de uma ação constitucional que permite "o conhecimento de informações relativas à pessoa do impetrante, constantes de registros ou bancos de dados de entidades governamentais ou de caráter público", "a retificação de dados, quando não se prefira fazê-lo por processo sigiloso, judicial ou administrativo" e "para a anotação nos assentamentos do interessado, de contestação ou explicação sobre dado verdadeiro mas justificável e que esteja sob pendência judicial ou amigável" (artigo $5^{\circ}$, LXXII, "a" e "b" e artigo $7^{\circ}$, III da Lei $n^{\circ}$ 9.507/1997, respectivamente).

Esse último diploma legal, inclusive, regulamenta o direito de acesso às informações e disciplina o rito processual do habeas data. Ele trata como de caráter público todos os registros ou banco de dados que contenham informações que possam ser transmitidas a terceiros ou que não sejam de uso exclusivo do órgão produtor ou depositário das informações.

O procedimento extrajudicial do habeas data consiste na apresentação de um requerimento ao órgão ou entidade depositária do registro ou banco de dados, o qual será deferido ou indeferido no prazo de quarenta e oito horas. Após esse prazo, a decisão será comunicada ao requerente 
em vinte e quatro horas. Se o pedido for deferido, o depositário do registro ou do banco de dados marcará dia e hora para que o requerente tome conhecimento das informações. Se, eventualmente, for verificada a inexatidão de quaisquer dados, o interessado, por meio de petição, poderá requerer a sua retificação, a qual será providenciada em no máximo dez dias a contar da entrada do requerimento. Se, porventura, o interessado desejar apresentar explicações ou contestações sobre os dados, ela será anotada no seu cadastro.

Se o requerimento extrajudicial for indeferido, o interessado poderá ingressar com uma ação judicial de habeas data a qual deverá ser devidamente instruída com provas da recusa de algumas das três situações que ensejam o cabimento da ação, a depender do caso. Se for julgada procedente, o juiz marcará data e horário para que o requerido apresente ao requerente as informações e/ou as retificações e/ou as anotações feitas no seu assentamento. Da sentença judicial de improcedência do pedido de habeas data cabe apelação. Essa ação é impetrada de forma gratuita e independe da existência de motivação, bastando somente o desejo de ter conhecimento das informações constantes na Administração Pública.

No âmbito da legislação ordinária brasileira, encontra-se em vigor, desde 18 de novembro de 2011, a Lei 12.527/2011, denominada Lei de Acesso à Informação (LAI). O conceito do termo informação está previsto em seu artigo $4^{\circ}$, I e se caracteriza como sendo os "dados, processados ou não, que podem ser utilizados para produção e transmissão de conhecimento, contidos em qualquer meio, suporte ou formato" (Brasil, 2011).

Decompondo a referida definição em seus elementos constitutivos, encontramos os seguintes termos de especial importância para a Ciência da Informação: dados, produção e transmissão de conhecimento, meio, suporte e formato.

Dessa forma, tem-se por dado "algo acontecido, realizado, feito, e que se tornou irrevogável ou necessário" (Semidão, 2014, p. 71), que, ao ser processado, gera informação. Já a produção de conhecimento é a atividade intelectual realizada pelo responsável por manipular os dados enquanto a transmissão do conhecimento é a sua divulgação a terceiros interessados ou não. Tais aspectos levam a concluir que, no contexto da LAI, somente os dados que podem ser utilizados para a produção e transmissão do conhecimento é que são considerados informação.
Relativamente a meio, suporte e formato, tem-se, por meio o "suporte ou material no qual são registrados dados, por exemplo: papel, disquete, disco rígido, CD-ROM, fita magnética" (Cunha; Cavalcanti, 2008, p. 242). O suporte, por sua vez, é o "objeto material, ou dispositivo, sobre o qual, ou no qual se encontram representados os dados ou informações; [...] material (ou dispositivo) ativo ou passivo que pode memorizar uma informação e restituí-la quando necessário" (Cunha; Cavalcanti, 2008, p. 352). Por fim, formato é a "descrição da representação física das informações, independentemente da sua representação codificada, p. ex.: livro, periódico ou mapa" (Cunha; Cavalcanti, 2008, p. 173).

Esse conceito é uma reprodução literal do conceito apresentado pelo artigo $3^{\circ}$, I do Decreto $n^{\circ}$ 7.724 de 16 de maio de 2012 - regulamento no âmbito federal da LAI - e o objetivo da lei ao conceituar institutos é o de "evitar a negativa de acesso à informação por meio de uma hermenêutica reducionista por parte do agente público obrigado a observar plenamente o direito" (Salgado, 2015, p. 88), já que é possível ocorrer a recusa dos agentes obrigados ao seu cumprimento em razão de uma má interpretação legislativa.

Além disso, e partindo para a análise do termo no âmbito jurisprudencial do Supremo Tribunal Federal (STF), identificamos que a palavra informação possui maior incidência em acórdãos proferidos anteriormente à LAl, o que permite inferir que, após o advento da lei, esse termo passou a ser usado de forma mais específica e parcimoniosa, não sendo mais utilizado como sinônimo indiscriminado de dado, suporte, mensagem ou conhecimento (Santos; Guimarães, 2016).

No mesmo trabalho citado acima observamos, ainda, após análise de conteúdo (Bardin, 2008) que o termo informação é utilizado pelo STF, em ordem decrescente de incidência, nos contextos de informação sobre algo (60 incidências), elementos de informação (41 incidências), liberdade de informação (41 incidências), direito à informação (21 incidências), peças de informação (8 incidências), acesso à informação (7 incidências) e informação jornalística (7 incidências).

\section{A dimensão conceitual da informação na Ciência da Informação}

A Ciência da Informação, ramo de estudo das Ciências Sociais Aplicadas, surgiu como campo de conhecimento mais especificamente a partir da década de 1960, fruto de todo um avanço tecnológico que se fazia sentir no pós-guerra e em muito influenciada pelas ideias de Vannevar 
Bush, em seu legendário artigo As we may think, de 1945 (Bush, 1945).

Como destaca Borko (1968, p. 3, tradução nossa), a Ciência da Informação constitui "a disciplina que investiga as propriedades e o comportamento da informação, as forças que governam os fluxos de informação, e os significados do processamento da informação objetivando à acessibilidade e a usabilidade ótimas". Para tanto, o autor destaca que a Ciência da Informação se vale de conhecimentos que objetivam a organização, coleção, armazenamento, recuperação, interpretação, transmissão, transformação e utilização da informação. Nesse sentido, Tognoli e Guimarães (2011, p. 23) destacam, ainda, que a Ciência da Informação estuda os processos que objetivam a produção, a organização e o uso da informação registrada. Esse registro da informação, como ressaltado por Smit e Barreto (2002, p. 19) serve "para garantir sua permanência no tempo e portabilidade no espaço".

Ao buscar investigar como a informação se comporta e quais as suas propriedades, a Ciência da Informação, enquanto área de estudos, abrange espaços profissionais distintos, e em sua maioria fortemente ligados a aspaços insitucionais específicos, nos quais desenvolve aquilo que Fernandes (1995) denomina como gestão institucional dos saberes: a arquivologia, a biblioteconomia e a museologia. Smit (1993; 1999-2000) a elas metaforicamente se refere como as "3 Marias", em cujo âmbito as divergências ocorrem mais no nível terminológico que conceitual mas que guardam um importante ponto de convergência: o fato de trabalharem com a produção, a organização e uso de uma informação registrada.

Desde seu nascedouro, como se pode observar no texto seminal de Borko anteriomente citado, a Ciência da Informação se situa em um espaço interdisciplinar que interage com conhecimentos de diversos campos, como a Linguística, a Ciência da Computação, a Administração, a Estatística, o Direito, a Psicologia etc. No entanto, Guimarães (2008, p. 38) elenca algumas balizas que possam evidenciar a disciplinaridade da Ciência da Informação: o objeto, na informação registrada; o objetivo, na geração de conhecimento; os processos de geração (produção), organização e uso da informação registrada; os produtos, a partir da denominada informação documentária (Kobashi, 1994) e os instrumentos, via de regra exteriorizados em códigos, normas, sistemas de organziação etc.

A informação registrada como objeto de estudos da área constitui elemento de fundamental importância, pois é somente a partir dela que o cidadão, e a sociedade como um todo, poderão apoderar-se de forma segura de um conhecimento para que, após internalizado por um indivíduo e socializado com os demais, seja suscetível de constituir matéria-prima para a construção de um novo conhecimento, aspecto que Guimarães (2008) denomina como natureza helicoidal do conhecimento na Ciência da Informação.

Indo além, González de Gomez (1990, p. 121) refere-se à Ciência da Informação como uma área de estudos transdisciplinar cujo objeto reside nas "pragmáticas sociais de informação", ou, em outras palavaras, em " [...] um conjunto de regras e relações tecidas entre agentes, processos e produções simbólicas e materiais". Essa transdisciplinaridade decorre na necessidade intrínseca de agregar conhecimentos oriundos de diversas disciplinas para, a partir daí, construir um objeto de estudo e análise: a meta-informação e suas relações com a informação.

Cardoso (1996, p. 71) destaca que o termo informação sofreu, ao longo da História, inúmeras modificações quanto a sua acepção, a tal ponto de, em nossos dias, chegar às raias da ambiguidade, pois não raras vezes cai na vala comum dos dados, da comunicação, da instrução e, mais recentemente, do conhecimento.

A partir do fenômeno da explosão informacional, que sucedeu o período pós-guerra e causou forte impacto na sociedade, a informação passou a ocupar papel de centralidade no cotidiano da sociedade, sendo determinante em todos os aspectos da vida cultural, econômica, social etc., razão pela qual cada vez mais ela vem sendo estudada pelos diversos ramos da ciência. Ainda assim, a Ciência da Informação, da mesma forma que os demais ramos em que é utilizada a expressão, encontra dificuldades em obter consenso sobre o que realmente seja informação de tal forma que há vários conceitos ligados a esse termo.

Diretamente relacionada à linguagem, a informação, uma vez transmitida, propicia o processo comunicacional, cujo conteúdo se transmite a partir da linguagem, enquanto um sistema de estruturas em que a exteriorização das ideais dá-se por meio de símbolos (Berlo, 1997, p. 70) que, ao final, buscam organizar e comunicar o pensamento humano (Câmara Junior, 1959; Wurman, 1991).

Essa comunicação, cuja base etimológica remete ao "tornar comum, estabelecer comunhão, participar da comunidade, através do intercâmbio de informações" (Melo, 1977, p. 14), 
por sua vez, somente se efetiva a partir da existência de um dado conteúdo - a informação - esta considerada sua matéria-prima (Wurman, 1991) e sua motivação básica para que algo possa ser transmitido de uma mente que, por sua vez, a receberá como informação nova. Semidão (2014, p. 77) ressalta que "o termo informação está invariavelmente relacionado ao conhecimento e à comunicação, independentemente da motivação que suscita o ato de informar".

Nesse contexto de um conteúdo transmitido em um processo de comunicação, essencial se torna a menção à Teoria Matemática da Comunicação desenvolvida por Shannon e Weaver (1975) para os quais a informação é "uma mensagem enviada por um emissor para um receptor" (Logan, 2012, p. 27). Para tanto, implica um processo de comunicação que pressupõe a existência de um emissor, um sinal, um canal, uma mensagem, um receptor e, ainda os ruídos que daí possam decorrer.

Sem uma preocupação semântica acerca da informação a ser transmitida, a Teoria Matemática da Comunicação centra-se nos aspectos quantitativos relacionados à transmissão, com o objetivo de reduzir os gastos na comunicação eletrônica. Nessa linha de pensamento, Gleick (2013) entende que a informação é contabilizada em bits, os quais entende serem as unidades elementares da informação. Assim, os bits, uma vez assimilados pelas pessoas, configuram uma informação nova. Gleick defende a tese de que a informação está contida em todas as coisas, dentro e fora da ciência, generalizando que "a informação é aquilo que alimenta o mundo: o sangue e o combustível, o princípio vital" (Gleick, 2013 , p. 16). Ainda que historicamente importante para a configuração da Ciência da Informação, a Teoria Matemática da Comunicação tem sua aplicabilidade mais diretamente relacionada à Engenharia da Comunicação, utilizando-se de conhecimentos de probabilidade e de estatística para fundamentar seus problemas, de modo que as linguagens ordinárias existentes na comunicação são substituídas por equações matemáticas.

Partindo das definições mais comumente aceitas sobre o termo, em seu sentido geral, como "1. Ação ou efeito de informar-se; 2. opinião sobre alguém; 3. instrução; 4. direção" (Amora, 2009, p. 389), a informação, na Ciência da Informação, vai além do "sinônimo de mensagem, notícias, fatos, eventos e idéias que são adquiridos e passados adiante como conhecimento" (Machado, 2003, p. 15) para assumir uma dimensão ao mesmo tempo complexa e específica.
Cunha e Cavalcanti (2008, p. 201) definem informação como "um conhecimento que pode ser necessário a uma decisão", de onde decorre a informação registrada como "expressão que em sentido amplo abrange todas as espécies documentárias que possuam conteúdo informativo, independentemente do suporte físico dessas espécies" (Cunha e Cavalcanti, 2008, p. 204).

Etimologicamente destacada por Logan (2012, p. 26) como a ação de "dar uma forma para a mente”, a informação, para Le Coadic (1996) é um conhecimento inscrito que se utiliza de sistemas de signos (a linguagem) gravados em um suporte de modo a comportar um elemento de sentido. Em outras palavras, podemos dizer que a informação é um conhecimento transmitido a um ser consciente através de uma mensagem registrada, de modo a considerá-la, no âmbito da Ciência da Informação, como parte integrante de um processo comunicativo que pressupõe a existência um fluxo helicoidal de produção, organização e uso (Guimarães, 2008).

Nesse sentido, o conhecimento é o objetivo pretendido pela informação, de modo que é inútil referir-se à informação sobre algo que já conhecemos (Rapoport, 1970). Le Coadic (1996, p. 6) explica que a informação se transforma em "desinformação quando o conhecimento inscrito é alterado, falsificado (informação falsa), ou está ausente (não-informação)".

Nesse sentido, e como já destacado anteriormente, Fernandes (1995) refere-se a um elemento dinâmico, a gestão institucional dos saberes enquanto um conjunto de procedimentos ou ações que pretendem selecionar, sumarizar e organizar o conhecimento contido nas instituições (bibliotecas, arquivos etc.) com o intuito de produzir informação a fim de (re) ligar conhecimentos que, em razão da grande quantidade de informações produzidas, tenham sido separados.

Buckland (1991, p. 351) é quem, de forma mais sistemática, categoriza a informação em três dimensões, nomeadamente: como processo, como conhecimento e como coisa. Assim, para o autor, a informação-como-processo refere-se ao ato de informar, de comunicar algo a alguém. $\mathrm{Na}$ segunda acepção, a informação-como-conhecimento, tem-se a assimilação de algo durante o processo anterior, ou seja, é algo transmitido a alguém que aumenta o conhecimento e, consequentemente, diminui a incerteza do sujeito sobre algo. Por fim, a terceira e última acepção, informação-como-coisa, compreende tanto objetos quanto documentos que apresentam e exteriorizam conteúdo informacional. 
Nesse sentido, para o autor, a informação-comoprocesso refere-se ao ato de informar, de comunicar algo a alguém. Ocorre quando o conhecimento de alguém é modificado em razão da informação recebida. Ela é circunstancial. Isso significa que "quaisquer objetos particulares, documentos, dados ou eventos podem ser considerados como informativos dependendo das circunstâncias" (Buckland, 1991, p. 10, tradução nossa).

$\mathrm{Na}$ segunda acepção, a informação-comoconhecimento, tem-se a assimilação da informação transmitida durante 0 processo anterior e, como consequência, há redução de incertezas sobre determinado fato. Outras vezes, porém, a informação gera um aumento de incertezas. Destaca-se que a principal característica da informação-como-conhecimento é que ela é intangível - que não se pode tocar ou medir. Todavia, Buckland (1991) ressalta que essas informações devem estar, de alguma forma física, representadas como um sinal, texto ou comunicação, por exemplo. A partir daí é que surge a terceira acepção: a informação-como-coisa.

Dessa forma, a informação-como-coisa, compreende tanto textos quanto documentos que apresentam e exteriorizam conteúdo informacional. Buckland (1991, p. 2, tradução nossa) ressalta que diversos teóricos não aprovam o uso do termo informação nesse contexto, que também se relaciona diretamente com os sistemas de informação e de recuperação da informação. O propósito da informação-como-coisa é:

[...] esclarecer seu significado em relação a outros usos do termo informação; estabelecer a regra fundamental de informação-como-coisa no sistema de informação; e considerar o possível uso da noção de informação-como-coisa trazendo ordem teórica a campos heterogêneos, mal-ordenados associados com a 'ciência da informação'.

Silva e Ribeiro (2002, p. 37) vinculam a representação e o registro da informação à aceitabilidade social dos símbolos utilizados e à possibilidade de esses ficarem sedimentados em distintos suportes materiais, tais como papel, disco magnético etc. Isso leva a uma relação necessária entre informação (o conteúdo) e documento (o continente), este último materializando-se, como já destacava Otlet (1934), em uma forma diversificada, como livros, periódicos, peças de conjuntos de arquivos, estampas, fotografias, objetos, partituras, filmes, discos, amostras, modelos, fac-símiles, enfim, "tudo que tenha caráter representativo em três dimensões e, eventualmente, em movimento" (Cunha; Cavalcanti, 2008, p. 132).
Se, por um lado, a Ciência da Informação confere ao documento uma acepção ampla e diversificada, tanto em termos de conteúdo quanto de forma, tal não ocorre no Direito, em que o documento constitui "a prova escrita oferecida em juízo para demonstração do fato ou do direito alegado" (Silva, 2007, p. 493). Dessa forma, o documento insere-se no terreno probatório (a prova documental), em paralelo à prova testemunhal. No entanto, e uma vez constituindo meio de prova, o documento, juridicamente entendido, pode manifestar-se em diferentes continentes, como é o caso da fotografia ou de uma gravação, quando utilizadas como provas em um processo criminal. Assim, e antes de constituir ou não elementos probatórios, o documento, para o Direito, constitui a representação material de um ato/fato, capaz de gerar consequências (a lide ou o conflito de interesses resistidos) na esfera jurídica.

Em síntese, pode-se observar que a informação, "considerada a quinta necessidade do homem, precedida por ar, água, alimentação e abrigo" (Octaviano, Rey e Silva, 1999, p. 175), pressupõe uma ideia (conteúdo), materializada em um suporte (registro) e que serve para fins comunicativos (transmissão) de forma a gerar conhecimento.

\section{Apresentação, análise e discussão dos resultados}

Apresentam-se, a seguir, as categorias de análise, dentro das quais tem-se os traços descritivos encontrados bem como o campo (Direito - D ou Ciência da Informação - Cl) em que são tratados).

\begin{tabular}{c}
\hline Categoria: Processos que incidem sobre a informação \\
\hline acesso $(\mathrm{D})$ \\
\hline apropriação $(\mathrm{Cl})$ \\
\hline armazenamento $(\mathrm{Cl})$ \\
\hline coleção $(\mathrm{Cl})$ \\
\hline comunicação $(\mathrm{Cl})$ \\
\hline contabilização em bits $(\mathrm{Cl})$ \\
\hline contestação $(\mathrm{D})$ \\
\hline geração / produção $(\mathrm{Cl})$ \\
\hline instrução $(\mathrm{Cl})$ \\
\hline intercâmbio $(\mathrm{Cl})$ \\
\hline interpretação $(\mathrm{Cl})$ \\
\hline materialização $(\mathrm{Cl})$ \\
\hline organização $(\mathrm{Cl})$ \\
\hline recuperação $(\mathrm{Cl})$
\end{tabular}




\begin{tabular}{|c|}
\hline registro $(\mathrm{Cl})$ \\
\hline representação (Cl) \\
\hline socialização $(\mathrm{Cl})$ \\
\hline transformação $(\mathrm{Cl})$ \\
\hline transmissão (D / Cl) \\
\hline uso $(\mathrm{Cl})$ \\
\hline Categoria: Elementos / componentes da informação \\
\hline canal $(\mathrm{Cl})$ \\
\hline conteúdo $(\mathrm{Cl})$ \\
\hline dados $(\mathrm{Cl})$ \\
\hline emissor $(\mathrm{Cl})$ \\
\hline fluxo $(\mathrm{Cl})$ \\
\hline formatos (D) \\
\hline linguagem $(\mathrm{Cl})$ \\
\hline meios (D) \\
\hline mensagem $(\mathrm{Cl})$ \\
\hline órgão depositário (D) \\
\hline órgão produtor (D) \\
\hline registros $(D)$ \\
\hline ruídos $(\mathrm{Cl})$ \\
\hline sentido $(\mathrm{Cl})$ \\
\hline signos $(\mathrm{Cl})$ \\
\hline símbolos $(\mathrm{Cl})$ \\
\hline sinal $(\mathrm{Cl})$ \\
\hline suporte $(\mathrm{D} / \mathrm{Cl})$ \\
\hline $\begin{array}{l}\text { Categoria: Características / atributos / } \\
\text { propriedades da informação }\end{array}$ \\
\hline acessibilidade $(\mathrm{Cl})$ \\
\hline atinência $(\mathrm{Cl})$ \\
\hline ausência $(\mathrm{Cl})$ \\
\hline caráter vinculante (D) \\
\hline comportamento da informação $(\mathrm{Cl})$ \\
\hline desinformação / não-informação (Cl) \\
\hline falsidade $(\mathrm{Cl})$ \\
\hline imprescritibilidade (D) \\
\hline inalienabilidade (D) \\
\hline informação como matéria-prima $(\mathrm{Cl})$ \\
\hline informação como mensagem $(\mathrm{Cl})$ \\
\hline informação documentária $(\mathrm{Cl})$ \\
\hline informação-como-coisa (Cl) \\
\hline informação-como-processo $(\mathrm{Cl})$ \\
\hline licitude (D) \\
\hline necessidade $(\mathrm{Cl})$ \\
\hline novidade $(\mathrm{Cl})$ \\
\hline
\end{tabular}

\begin{tabular}{|c|}
\hline obrigatoriedade (D) \\
\hline permanência $(\mathrm{Cl})$ \\
\hline portabilidade $(\mathrm{Cl})$ \\
\hline publicidade (D) \\
\hline registro $(\mathrm{Cl})$ \\
\hline sigilo (D) \\
\hline universalidade (D) \\
\hline usabilidade $(\mathrm{Cl})$ \\
\hline Categoria: Objetivo \\
\hline acesso a documentos (D) \\
\hline acesso ao conhecimento (D) \\
\hline alteração do conhecimento $(\mathrm{Cl})$ \\
\hline transmissão do conhecimento $(\mathrm{D} / \mathrm{Cl})$ \\
\hline geração/ produção de conhecimento $(\mathrm{Cl})$ \\
\hline gestão institucional dos saberes $(\mathrm{Cl})$ \\
\hline produção de documentos (D) \\
\hline $\begin{array}{l}\text { Categoria: Direitos e garantias } \\
\text { decorrentes da Informação }\end{array}$ \\
\hline direito à privacidade $(D)$ \\
\hline direito de informar (D) \\
\hline direito de obtenção de certidões (D) \\
\hline direito de ser informado (D) \\
\hline direito fundamental (D) \\
\hline habeas data $(D)$ \\
\hline inviolabilidade da honra (D) \\
\hline inviolabilidade da imagem (D) \\
\hline inviolabilidade da intimidade (D) \\
\hline inviolabilidade da vida privada (D) \\
\hline irrenunciabilidade (D) \\
\hline liberdade de impressa (D) \\
\hline liberdade de informação (D) \\
\hline
\end{tabular}

Tabela I

Como se pode observar, o Direito atribui poucos processos à informação, se comparado à Ciência da Informação, nomeadamente o acesso, a contestação e a transmissão. Isso revela em que medida essa temática é ainda nova para o Direito, em especial por meio das questões legais relacionadas à transparência administrativa que, por sua vez, impõem um franqueamento do acesso da informação aos cidadãos, o direito do cidadão de contestar uma informação falsa a seu respeito e que possa lhe causar danos, e, ainda, a transmissão da informação, seja como pressuposto do acesso seja, ainda, como processo que, a exemplo da situação anterior, igualmente pode causar 
dano ao cidadão. Já no caso da Ciência da Informação, esses processos assumem uma natureza mais operacional, enquanto etapas - muitas vezes sequencias - de um continuum ligado à trilogia produção, organização e uso da informação (Guimarães, 2008).

No que tange aos elementos da informação, o Direito volta-se mais especificamente para a informação enquanto documento, ou "informação como coisa" postulada por Buckland (1991), ao se referir a formatos, registros, suportes e aos órgãos produtor e depositário, ao passo que a $\mathrm{Ci}$ ência da Informação volta-se para aspectos mais intangíveis, seja ligados ao processo comunicacional em si (emissor, receptor, conteúdo, canal, fluxo, mensagem, meios, linguagem, signos, símbolos e sinais), seja a aspectos mais específicos, que se refletem na recuperação tais como os ruídos e a formação de sentido.

A categoria características / atributos / propriedades da informação, por sua vez, assume, no Direito, uma abordagem mais ligada a questões que podem se aquilatadas processualmente, tais como caráter vinculante, imprescritibilidade, inalienabilidade, licitude, obrigatoriedade, publicidade, sigilo e universalidade. Já na Ciência da Informação, discute-se se essa informação pode ser, entre outros aspectos, acessível, utilizável, relevante, portável, inovadora, permanente, necessária, verdadeira ou falsa, presente ou ausente, registrada, ou, reportando-se a Michael Buckland, se pode ser encarada como coisa ou como processo.

Os objetivos da informação, por sua vez, igualmente revelam uma abordagem mais material ou concreta por parte do Direito e mais abstrata da Ciência da Informação, visto que o primeiro se volta prioritariamente aos documentos (produção e acesso) ao passo que a Ciência da Informação centra sua ênfase maior no conhecimento, que pode ser produzido, alterado, gerido e transmitido.

Por último, tem-se, juridicamente, um conjunto de direitos e garantias decorrentes da informação, tais como a privacidade, a obtenção de certidões, o habeas data, a liberdade de imprensa, e a inviolabilidade da honra, da imagem e da intimidade.

Indo além das categorias de análise estabelecidas, observa-se, ainda, na Ciência da Informação, uma recorrente associação da informação com dado (acesso a dados, bancos de dados, dados processados e não processados, assim como inexatidão, retificação e veracidade de dados) e com documento (anotação em assentamentos, espécies documentárias e os processos de arquivamento, avaliação, classificação, eliminação, gestão, guarda, recolhimento, tramitação e uso de documentos).

Uma análise das categorias apresentadas revela pouca convergência entre o Direito e a Ciência da Informação no que tange à informação. Tal aspecto reitera a complementaridade entre ambas as áreas quando da abordagem dessa temática. Nesse contexto, tem-se, como elementos coincidentes, apenas a informação como processo (o ato de informar-se ou informar a alguém) e a transmissão de conhecimento como objetivo da informação, bem como a necessidade de um suporte para que essa informação tenha materialidade e, portanto, possa ser percebida e utilizada.

No que tange às especificidades de cada área, observa-se, na Ciência da Informação, uma maior ênfase nos processos que incidem sobre a informação, revelando aquilo que Guimarães (2008) denomina como fluxo helicoidal, a partir dos macroprocessos de produção, organização e uso da informação. A isso se alia a presença das dimensões conceituais da informação: como conhecimento, como processo e como coisa (Buckland, 1991).

No caso do Direito, tem-se, por sua vez, uma ênfase nos efeitos ou garantias decorrentes do acesso à informação (por exemplo: habeas data, liberdade de imprensa etc.) e a características que, por sua vez, revelam princípios jurídicos inerentes ao direito à informação (por exemplo: irrenunciabilidade, publicidade, universalidade etc.).

\section{Considerações finais}

Se, por um lado, no âmbito jurídico, a informação é um direito fundamental do ser humano, por outro, o termo é utilizado em diversas acepções, ora referindo-se à informação sobre algo, ora aos elementos de informação ou, ainda, sobre o direito de acesso à informação, dentre outros. Nesse contexto, ainda se mantém uma concepção mais tradicional de informação, eminentemente voltada a sua materialização enquanto documento enquanto a Ciência da Informação vai além, ao abordar questões ligadas ao conteúdo informacional.

Se, no âmbito da Ciência da Informação, ainda não existe consenso sobre o que efetivamente seja informação, alguns elementos comuns podem ser aventados, a partir da pesquisa realizada, tais como o fato de constituir a matériaprima do conhecimento, de pressupor uma dimensão mais ativa (informar alguém sobre algo) e mais reflexiva (informar-se sobre algo) e, prin- 
cipalmente, de pressupor um continuum de processos que vai desde a geração até o uso, tendo na organização seu elemento-ponte.

\section{Referências}

Amora, Antônio Soares (2009). Minidicionário Soares Amora da língua portuguesa. São Paulo: Saraiva, 2009.

Bardin, Laurence (2008). Análise de Conteúdo. Lisboa: Edições 70, 2008.

Berlo, David Kenneth (1997). O processo da comunicação: introdução à teoria e à prática. $8^{a}$ ed. São Paulo: Martins Fontes, 1997.

Borko, Harold (1968). Information Science: what is it? American Documentation. 19:1 (1968) 3-5.

Brasil (1988). Constituição Federal (1988). Constituição da República Federativa do Brasil. Promulgada em 5 out. 1988. Brasília, DF, Senado Federal, 5 out. 1988. http://www.planalto.gov.br/ccivil_03/constituicao/constituicaocompilado.htm (2016-10-14).

Brasil (2011). Congresso Nacional. Lei $n^{\circ} 12.527$ de 18 de novembro de 2011. Regula o acesso a informações previsto no inciso XXXIII do art. $5^{\circ}$, no inciso II do $\S 3^{\circ}$ do art. 37 e no $\S 2^{\circ}$ do art. 216 da Constituição Federal; altera a Lei $n^{\circ} 8.112$, de 11 de dezembro de 1990; revoga a Lei $n^{\circ}$ 11.111, de 5 de maio de 2005, e dispositivos da Lei $n^{\circ}$ 8.159, de 8 de janeiro de 1991; e dá outras providências. Diário Oficial da União, Poder Executivo, Brasília, DF, 18 nov. 2011 - edição extra. http://www.planalto.gov.br/ccivil_03/_ato2011-2014/2011/lei//12527.htm (2016-09-18).

Brasil (2013. Ministério da Ciência, Tecnologia e Inovação. Portaria MCTI n² 293, de 01.04.2013. Institui a Política de Gestão Documental no âmbito do Ministério da Ciência, Tecnologia e Inovação. Brasília, DF, 1 abr. 2013. http://cnpq.br/gestao-de-documentos (2016-10-20).

Buckland, Michael Keeble (1991). Information as thing. Journal of the American Society for Information Science. 45:5 (1991) 351-360.

Bush, Vannevar (1945). As we may think. Atlantic Monthly. 176:1 (1945) 101-108.

Câmara Junior, Joaquim Mattoso (1959). Princípios de lingüística geral. $3^{a}$ ed. Rio de Janeiro: Livraria Acadêmica, 1959.

Cunha, Murilo Bastos da; Cavalcanti, Cordélia Robalinho de Oliveira (2008). Dicionário de Biblioteconomia e Arquivologia. Brasília: Briquet de Lemos/Livros, 2008.

Gil, Antônio Carlos (2014). Métodos e técnicas de pesquisa social. 6 ${ }^{a}$ ed. São Paulo: Atlas, 2014.

Gleick, James (2013). A informação: uma história, uma teoria, uma enxurrada. São Paulo: Companhia das Letras, 2013.

González de Gomez, Maria Nélida (1990). O objeto de estudo da Ciência da Informação: paradoxos e desafios. Ciência da Informação. 19:2 (1990) 117-122.

Guimarães, José Augusto Chaves (2008). Ciência da Informação, Arquivologia e Biblioteconomia: em busca do necessário diálogo entre o universo teórico e os fazeres profissionais. // Fujita, Mariângela Spotti Lopes; Guimarães, José Augusto Chaves (orgs.) (2008). Ensino e Pesquisa em Biblioteconomia no Brasil: a emergência de um novo olhar. São Paulo: Cultura Acadêmica, 2008. 33-44.

Guimarães, José Augusto Chaves; Sales, Rodrigo de (2010). Análise Documental: concepções do universo acadêmico brasileiro em Ciência da Informação. DataGramaZero Revista de Ciência da Informação. 11:1 (2010) 1-17.
Kobashi, Nair Yumiko (1994). A elaboração de informações documentárias: em busca de uma metodologia. 1994. Tese de doutorado.

Le Coadic, Yves-François (1996). A ciência da informação. Brasília: Briquet de Lemos/Livros, 1996.

Lenza, Pedro (2015). Direito Constitucional esquematizado. $19^{a}$ ed. São Paulo: Saraiva, 2015.

Logan, Robert K. (2012). Que é informação?: a propagação da organização na biosfera, na simbolosfera, na tecnosfera e na econosfera. Rio de Janeiro: Contraponto; PUCRio, 2012.

Machado, Ana Maria Nogueira (2003). Informação e controle bibliográfico: um olhar sobre a cibernética. São Paulo: UNESP, 2003.

Melo, José Marques de (1977). Comunicação social: teoria e pesquisa. Petrópolis: Vozes, 1977

Novelino, Marcelo (2011). Direito Constitucional. $5^{\mathrm{a}}$ ed. São Paulo: Método, 2011.

Octaviano, Vera Lúcia de Campos; Rey, Carla Monte; Silva, Kelly Cristina da (1999). A informação na atividade técnico-científica: em enfoque pós-moderno. Translnformação. $11: 2$ (1999) 173-184.

Rapoport, Anatol (1970). What is information? // Saracevic, Tefko (1970). Introdution to information science. Nova York: Bowker, 1970.

Salgado, Eneida Desiree (2015). Lei de Acesso à Informação (LAI): comentários à Lei $n^{\circ} 12.527 / 2011$ e ao Decreto $n^{\circ}$ 7.724/2012. São Paulo: Atlas, 2015.

Santos, João Carlos Gardini; Guimarães, José Augusto Chaves (2016). As dimensões temáticas da informação na jurisprudência brasileira: uma análise a partir dos acórdãos do Supremo Tribunal Federal do Brasil. // Neto, Luísa; Ribeiro, Fernanda (orgs.) (2016). Direito e Informação na Sociedade em Rede: atas. Faculdade de Direito e Faculdade de Letras da Universidade do Porto: Porto, 2016. 408-418.

Semidão, Rafael Aparecido Moron (2014). Dados, Informação e Conhecimento enquanto elementos de compreensão do universo conceitual da Ciência da Informação: contribuições teóricas. 2014. Tese de doutorado.

Silva, De Plácido e (2007). Vocabulário Jurídico. 27. ed. Rio de Janeiro: Forense, 2007.

Smit, Johanna Wilhelmina (1993). O documento audiovisual ou a proximidade entre as 3 Marias. Revista Brasileira de Biblioteconomia e Documentação. 26:1/2 (1993) 81-85.

Smit, Johanna Wilhelmina (1999-2000). Arquivologia, Biblioteconomia e Museologia: o que agrega estas atividades profissionais e o que as separa? Revista Brasileira de Biblioteconomia e Documentação. 1:2 (1999-2000) 27-36.

Smit, Johanna Wilhelmina; Barreto, Aldo de Albuquerque (2002). Ciência da Informação: base conceitual para a formação do profissional. // Valentim, Marta Lígia Pomim (Org.) (2002). Formação do Profissional da Informação. São Paulo: Polis, 2002.

Tognoli, Natália Bolfarini; Guimarães, José Augusto Chaves (2011). A organização do conhecimento arquivístico: perspectivas de renovação a partir das abordagens científicas canadenses. Perspectivas em Ciência da Informação. $16: 1$ (2011) 21-44.

Enviado: 2017-03-28. Segunda versión: 2017-07-25. Aceptado: 2018-09-14. 